\title{
Starch and oil in the donor cow diet and starch in substrate differently affect the in vitro ruminal biohydrogenation of linoleic and linolenic acids
}

\author{
A. Zened, ${ }^{\dagger}$ A. Troegeler-Meynadier, ${ }^{*} \dagger$ M. C. Nicot, ${ }^{\dagger} \dagger$ S. Combes, ${ }^{\star}$ L. Cauquil, ${ }^{*}$ Y. Farizon, ${ }^{*} \dagger$ and F. Enjalbert ${ }^{\star}{ }^{1}$ \\ *INRA, Unité Mixte de Recherche (UMR) 1289, Tandem, F-31326 Castanet-Tolosan, France \\ †Université de Toulouse, Institut National Polytechnique (INP), École Nationale Supérieure Agronomique de Toulouse (ENSAT), École Nationale \\ Vétérinaire de Toulouse (ENVT), UMR1289 Tandem, F-31076 Toulouse, France
}

\section{ABSTRACT}

Trans isomers of fatty acids exhibit different health properties. Among them, trans-10,cis-12 conjugated linoleic acid has negative effects on milk fat production and can affect human health. A shift from the trans-11 to the trans-10 pathway of biohydrogenation $(\mathrm{BH})$ can occur in the rumen of dairy cows receiving high-concentrate diets, especially when the diet is supplemented with highly unsaturated fat sources. The differences of $\mathrm{BH}$ patterns between linoleic acid (LeA) and linolenic acid ( $\operatorname{LnA})$ in such ruminal conditions remain unknown; thus, the aim of this work was to investigate in vitro the effects of starch and sunflower oil in the diet of the donor cows and starch level in the incubates on the BH patterns and efficiencies of LeA and LnA. The design was a $4 \times 4$ Latin square design with 4 cows, 4 periods, and 4 diets with combinations of 21 or $34 \%$ starch and 0 or $5 \%$ sunflower oil. The rumen content of each cow during each period was incubated with 4 substrates, combining 2 starch levels and either LeA or LnA addition. Capillary electrophoresis single-strand conformation polymorphism of incubates showed that dietary starch decreased the diversity of the bacterial community and the high-starch plus oil diet modified its structure. High-starch diets poorly affected isomerization and first reduction of LeA and LnA, but decreased the efficiencies of trans-11,cis-15-C18:2 and trans C18:1 reduction. Dietary sunflower oil increased the efficiency of LeA isomerization but decreased the efficiency of trans $\mathrm{C} 18: 1$ reduction. An interaction between dietary starch and dietary oil resulted in the highest trans-10 isomers production in incubates when the donor cow received the high-starch plus oil diet. The partition between trans-10 and trans-11 isomers was also affected by an interaction between starch level and the fatty acid added to the incubates, showing that the trans-10 shift only occurred with LeA, whereas LnA was mainly

Received April 27, 2011.

Accepted July 25, 2011.

${ }^{1}$ Corresponding author: f.enjalbert@envt.fr hydrogenated via the more usual trans-11 pathway, whatever the starch level in the substrate, although the bacterial communities were not different between LeA and LnA incubates. In LeA incubates, trans-10 isomer production was significantly related to the structure of the bacterial community.

Key words: rumen biohydrogenation, linoleic acid, linolenic acid, trans-10 shift

\section{INTRODUCTION}

Ruminal biohydrogenation (BH) intermediates of polyunsaturated fatty acids (FA) have important but contrasting effects on both dairy cows and human consumers. Among conjugated linoleic acids (CLA), trans-10, cis-12-CLA has strong negative effects on milk fat production by dairy cows (Baumgard et al., 2001) and can have adverse effects on human health (Tricon et al., 2004; Ip et al., 2007), but is usually present at very low concentrations in milk fat. On the contrary, cis-9,trans-11-CLA has positive effects on human health (Tricon et al., 2004; Ip et al., 2007). Milk cis9,trans-11-CLA, which is usually the predominant CLA isomer, mainly originates from a mammary desaturation of trans-11-C18:1 (Griinari et al., 2000), another intermediate of polyunsaturated $\mathrm{FA} \mathrm{BH}$.

The most abundant $\mathrm{BH}$ intermediates in the rumen and in ruminant products are trans-11 isomers, but a shift from the trans- 11 to the trans- 10 pathway of $\mathrm{BH}$ can occur, with high-concentrate diets supplemented either with high linoleic acid (LeA; Roy et al., 2006) or high $\alpha$-linolenic acid $(\operatorname{LnA}$; Loor et al., 2004; Pottier et al., 2006) fat sources. This shift is, at least in part, linked to the low $\mathrm{pH}$ observed with high-concentrate diets (Piperova et al., 2002; Troegeler-Meynadier et al., 2003). The BH pathway leading to trans-10 isomers has been well described with LeA, but trans-10 isomer production during $\mathrm{LnA} \mathrm{BH}$ has not yet been demonstrated. Besides, the trans-10 shift of $\mathrm{BH}$ pathway due to a high-starch diet is associated with a lowered milk fat content, and recent studies indicate specific changes of ruminal microbiota in cows exhibiting this milk fat 
Table 1. Ingredients and chemical composition of incubation substrates

\begin{tabular}{|c|c|c|c|c|}
\hline \multirow[b]{2}{*}{ Item } & \multicolumn{4}{|c|}{ Incubation substrate $^{1}$} \\
\hline & LSLeA & HSLeA & LSLnA & HSLnA \\
\hline \multicolumn{5}{|c|}{ Ingredient, $\mathrm{g}$ of DM per flask } \\
\hline Corn leaves and stems & 1.07 & 0.55 & 1.07 & 0.55 \\
\hline Corn grain & 0.68 & 0.34 & 0.68 & 0.34 \\
\hline Alfalfa hay & 0.39 & 0.00 & 0.39 & 0.00 \\
\hline Wheat & 0.00 & 1.31 & 0.00 & 1.31 \\
\hline Soybean meal & 0.44 & 0.35 & 0.44 & 0.35 \\
\hline $99 \%$ pure free $\mathrm{LeA}^{2}$ & 0.09 & 0.09 & 0.00 & 0.00 \\
\hline $99 \%$ pure free $\operatorname{LnA}^{2}$ & 0.00 & 0.00 & 0.09 & 0.09 \\
\hline \multicolumn{5}{|l|}{ Composition, $\%$ of DM } \\
\hline $\mathrm{NDF}$ & 37.8 & 26.5 & 37.8 & 26.5 \\
\hline Starch & 18.3 & 40.9 & 18.3 & 40.9 \\
\hline C18:0 & 0.04 & 0.03 & 0.04 & 0.03 \\
\hline cis-9-C18:1 & 0.22 & 0.20 & 0.22 & 0.20 \\
\hline LeA & 3.96 & 4.11 & 0.62 & 0.73 \\
\hline LnA & 0.05 & 0.10 & 3.39 & 3.48 \\
\hline
\end{tabular}

${ }^{1} \mathrm{LSLeA}=$ low starch $(\mathrm{LS})+$ free linoleic acid $(\mathrm{LeA}) ; \mathrm{HSLeA}=$ high starch $(\mathrm{HS})+$ free LeA; LSLnA $=$ LS + free $\alpha$-linolenic acid $(\operatorname{LnA}) ; \mathrm{HSLnA}=\mathrm{HS}+$ free $\operatorname{LnA}$.

${ }^{2}$ Sigma Co., St. Louis, MO.

depression (Weimer et al., 2010). Moreover, dietary polyunsaturated FA also affect ruminal microbiota, decreasing the amount of some fibrolytic bacteria, including Butyrivibrio fibrisolvens, the main ruminal biohydrogenating bacterium, and the negative effects of linseed oil are more important than those of sunflower oil, suggesting that LnA is more inhibiting than LeA (Yang et al., 2009).

Relative effects of ruminal microbiota, dietary starch level and fermentation substrates in this trans-10 shift when diets are enriched with both concentrate and polyunsaturated FA have not been clearly separated. Moreover, the differences of BH patterns between LeA and LnA in a ruminal milieu inducing this trans-10 shift have not been elucidated. The aim of this study was to investigate this shift in vitro, using donor cows receiving different combinations of dietary starch level and oil addition, including a high-starch plus oil diet intended to result in a trans-10 shift, and culture substrates with different starch levels and either LeA or LnA as a BH substrate.

\section{MATERIALS AND METHODS}

\section{In Vitro Cultures}

Four dry Holstein cows (average BW $650 \mathrm{~kg}$ at the beginning of the experiment) equipped with a ruminal cannula and housed in individual stalls were assigned to a $4 \times 4$ Latin square design, with 4 diets and 4 periods. The 4 diets were based on corn silage and contained soybean meal and a mineral mixture: a low-starch diet (21.5\% starch and $39.7 \%$ NDF, DM basis), containing alfalfa hay; a high-starch diet $(34.8 \%$ starch and $30.9 \%$
NDF), containing $49 \%$ of a wheat/barley mixture; an oil diet $(19.8 \%$ starch and $37.3 \%$ NDF) containing alfalfa hay and $5 \%$ sunflower oil; and a high-starch plus oil diet (33.1\% starch and $28.6 \% \mathrm{NDF}$ ), containing $49 \%$ wheat/barley and $5 \%$ sunflower oil. Cows received 12.5 $\mathrm{kg}$ of DM daily, in 2 equal meals at 0800 and 1700 h. Water was available ad libitum. The experimental periods lasted $28 \mathrm{~d}$. The cows received the control diet during the first 2 wk of each period and 1 of the 4 experimental diets during the last $2 \mathrm{wk}$.

Four incubation substrates were used: low starch with LeA, high starch with LeA, low starch with LnA, and high starch with LnA (Table 1). Because our objective was to study the BH pathways of LeA and $\mathrm{LnA}$, we used free $\mathrm{FA}$, not triglycerides, to avoid $\mathrm{BH}$ being affected by lipolysis.

In vitro incubations were performed on d 28. Ruminal fluid was taken from the 4 cows before the morning meal, strained through a metal sieve (1.6-mm mesh) and transferred quickly to the laboratory in anaerobic conditions at $39^{\circ} \mathrm{C}$. One hundred milliliters of each sample of ruminal juice was stored at $-18^{\circ} \mathrm{C}$ for subsequent analysis. A bicarbonate buffer solution (19.5 g of $\mathrm{Na}_{2} \mathrm{HPO}_{4} \cdot 12 \mathrm{H}_{2} \mathrm{O} / \mathrm{L}, 9.24 \mathrm{~g}$ of $\mathrm{NaHCO}_{3} / \mathrm{L}, 0.705 \mathrm{~g}$ of $\mathrm{NaCl} / \mathrm{L}, 0.675 \mathrm{~g}$ of $\mathrm{KCl} / \mathrm{L}, 0.108 \mathrm{~g}$ of $\mathrm{CaCl}_{2} \cdot 2 \mathrm{H}_{2} \mathrm{O} / \mathrm{L}$, and $0.180 \mathrm{~g}$ of $\mathrm{MgSO}_{4} \cdot 7 \mathrm{H}_{2} \mathrm{O} / \mathrm{L}$ ) was prewarmed at $39^{\circ} \mathrm{C}$, saturated with $\mathrm{CO}_{2}$, and acidified to a $\mathrm{pH}$ of 6.0 with 6 $N$ hydrochloric acid. The ruminal fluid from each cow was incubated with the 4 substrates, resulting in 16 incubation flasks that contained the substrate, $60 \mathrm{~mL}$ of ruminal fluid and $60 \mathrm{~mL}$ of buffer solution. The flasks were filled with $\mathrm{CO}_{2}$ and placed in a water bath rotary shaker (Aquatron; Infors AG, Bottmingen, Germany) at $39^{\circ} \mathrm{C}$. Flasks were then closed with a rubber cap 
with a plastic tube leading into the water to vent fermentation gas without allowing the ingress of oxygen. Flasks were stirred at $130 \mathrm{rpm}$ and kept safe from the light. After $5 \mathrm{~h}$ of incubation, flasks were placed into ice water to stop fermentations and the $\mathrm{pH}$ was measured. The contents of the flasks were then immediately frozen. Samples were freeze-dried (Virtis Freezemobile 25; Virtis Co. Inc., Gardiner, NY), weighed, ground and homogenized in a ball mill (Dangoumau; Prolabo, Nogent-sur-Marne, France), and kept at $-18^{\circ} \mathrm{C}$ for later analysis.

\section{FA Analysis}

Substrates and non-incubated and incubated ruminal fluids were analyzed for FA contents and profiles. The FA were extracted and methylated using the procedure of Park and Goins (1994), except that the solution of $14 \%$ boron trifluoride in methanol was replaced by a solution of methanol-acetyl chloride (10:1 vol/vol). Nonadecanoic acid (Sigma Co., St. Louis, MO) was used as the internal standard at a dose of $0.8 \mathrm{mg}$.

Fatty acid methyl esters were quantified by GC (Agilent $6890 \mathrm{~N}$, equipped with a model 7683 auto injector, Network GC System; Agilent Technologies Inc., Palo Alto, CA) using a fused silica capillary column (100 m $\times 0.25 \mathrm{~mm}$ i.d., $0.20-\mu \mathrm{m}$ film thickness; CPSil88; Varian Inc., Middelburg, the Netherlands). For analysis, the flame ionization detector temperature was maintained at $260^{\circ} \mathrm{C}$ and the injector at $255^{\circ} \mathrm{C}$; the split ratio was 1:50. Hydrogen was used as the carrier gas with a constant flow of $1 \mathrm{~mL} / \mathrm{min}$. The samples were injected in $1 \mu \mathrm{L}$ of hexane. The initial temperature of the oven was $60^{\circ} \mathrm{C}$, which was held for $2 \mathrm{~min}$; it was then increased by $8^{\circ} \mathrm{C} / \mathrm{min}$ to $150^{\circ} \mathrm{C}$, held at $150^{\circ} \mathrm{C}$ for $12 \mathrm{~min}$, increased by $2^{\circ} \mathrm{C} / \mathrm{min}$ to $175^{\circ} \mathrm{C}$, held at $175^{\circ} \mathrm{C}$ for $20 \mathrm{~min}$, increased by $5^{\circ} \mathrm{C} / \mathrm{min}$ to $225^{\circ} \mathrm{C}$, held at $225^{\circ} \mathrm{C}$ for $10 \mathrm{~min}$, and finally increased by $10^{\circ} \mathrm{C} /$ min to $240^{\circ} \mathrm{C}$ and maintained at $240^{\circ} \mathrm{C}$ for $10 \mathrm{~min}$. A second analysis was used to separate LnA from C20:1 and trans-13 + trans-14-C18:1 from cis-9-C18:1 with the same temperature of injector and detector as in the first analysis. The split ratio was 1:75 and hydrogen was the carrier gas with a constant pressure of 150 $\mathrm{kPa}$. The samples were injected in $1 \mu \mathrm{L}$ of hexane. The initial oven temperature was $60^{\circ} \mathrm{C}$, which was held for 3 min; it was then increased by $8^{\circ} \mathrm{C} / \mathrm{min}$ to $190^{\circ} \mathrm{C}$, held at $190^{\circ} \mathrm{C}$ for $13 \mathrm{~min}$, increased by $5^{\circ} \mathrm{C} / \mathrm{min}$ to $225^{\circ} \mathrm{C}$, held at $225^{\circ} \mathrm{C}$ for $10 \mathrm{~min}$, increased by $10^{\circ} \mathrm{C} / \mathrm{min}$ to a final temperature of $230^{\circ} \mathrm{C}$, and maintained there for $10 \mathrm{~min}$. Peaks were identified and quantified by comparison with commercial standards (Sigma Co.), except C18:1 FA other than trans-9-C18:1, trans-11-C18:1, and cis9-C18:1, which were identified by order of elution. The major peak of conjugated linolenic acid (CLnA) was identified by order of elution (Akraim et al., 2007). Additionally, using a standard mixture of CLA isomers (cis-9,trans-11,cis-15; and cis-9,trans-13,cis-15), kindly provided by P. Y. Chouinard (Université Laval, Québec, Canada), the GC method adapted to the separation of these 2 isomers (Gervais and Chouinard, 2008) could not detect the cis-9,trans-13,cis-15 isomer in our samples, so that CLnA will refer to cis-9,trans-11,cis-15 CLnA in this paper.

\section{Bacterial Community Analysis}

Total DNA was extracted and purified with QIAamp DNA Stool Mini kit (Qiagen Ltd., West Sussex, UK) from approximately $0.2 \mathrm{~g}$ of sample with a previous bead-beating step in a FastPrep Instrument (MP Biomedicals, Illkirch, France). Extraction of DNA, PCR reactions, and capillary electrophoresis single-strand conformation polymorphism (CE-SSCP) procedures were based on the procedure described by Privé et al. (2010). The temperature program of the PCR reaction was different and consisted of $2 \mathrm{~min}$ at $94^{\circ} \mathrm{C}, 30$ cycles of $30 \mathrm{~s}$ at $94^{\circ} \mathrm{C}, 15 \mathrm{~s}$ at $61^{\circ} \mathrm{C}, 15 \mathrm{~s}$ at $72^{\circ} \mathrm{C}$, and a final extension of $7 \mathrm{~min}$ at $72^{\circ} \mathrm{C}$.

The CE-SSCP data processing was computed with StatFingerprints software (Michelland et al., 2009), and CE-SSCP profiles were aligned using pairwise alignment of their internal standard with the same reference internal standard.

\section{Calculations}

The initial FA composition of each flask was calculated by adding the FA from ruminal fluids to the FA carried out by the substrates. All trans C18:1 isomers were summed to calculate trans C18:1, but only CLA isomers clearly known to be intermediates of LeA BH (i.e., trans-10,cis-12; cis-9,trans-11; and trans-9,trans11-CLA) were summed to calculate total CLA. The balances (negative value for disappearances and positive values for productions) were calculated for each FA as the difference between final and initial percentages.

The calculations of the LeA and LnA isomerization efficiencies (ELeA and ELnA, respectively) and the calculations of the CLA, CLnA, trans-11,cis-15-C18:2, and total trans C18:1 reduction efficiencies (ECLA, ECLnA, Et11c15, and Et18:1, respectively) were adapted from Troegeler-Meynadier et al. (2006).

For ruminal LeA biohydrogenation,

$$
\begin{gathered}
\text { ELeA }=\text { LeAb } / \text { LeAi } \\
\mathrm{ECLA}=(\operatorname{LeAb}+\mathrm{CLAb}) /(\mathrm{LeAb}+\mathrm{CLAi}),
\end{gathered}
$$


and for ruminal LnA biohydrogenation,

$$
\begin{gathered}
\mathrm{ELn} \mathrm{A}=\operatorname{LnAb} / \operatorname{LnAi}, \\
\mathrm{ECLnA}=(\operatorname{LnAb}+\mathrm{CLnAb}) /(\operatorname{Ln} \mathrm{Ab}+\mathrm{CLnAi}), \\
\mathrm{E} t 11 c 15=(\operatorname{LnAb}+\mathrm{CLnAb}+t 11 c 15 \mathrm{~b}) / \\
(\operatorname{LnAb}+\mathrm{CLnAb}+t 11 c 15 \mathrm{i}),
\end{gathered}
$$

where the b suffix refers to the difference between initial and final proportions; the i suffix refers to the initial proportions of each FA; and CLA and $t 11 c 15$ represent total CLA and trans-11,cis-15-C18:2, respectively.

The efficiency of the subsequent reduction, which is the same for the LeA and LnA BH, was calculated as

$$
\begin{gathered}
\mathrm{E} t 18: 1=(\operatorname{LeAb}+\mathrm{CLAb}+\operatorname{LnAb}+\mathrm{CLnAb} \\
+t 11 c 15 \mathrm{~b}+t 18: 1 \mathrm{~b}) /(\operatorname{LeAb}+\mathrm{CLAb}+\operatorname{LnAb} \\
+ \text { CLnAb }+t 11 c 15 \mathrm{~b}+t 18: 1 \mathrm{i}),
\end{gathered}
$$

where $t 18: 1$ represents total trans $\mathrm{C} 18: 1$.

To study the diversity of bacterial communities, the Simpson diversity index was calculated using the StatFingerprints software (Michelland et al., 2009) as

$$
\text { Simpson index }=-\log \sum a_{i}^{2},
$$

where $a_{i}$ corresponds to the relative abundance of each peak $(i)$.

It is considered as a dominance index because it weights toward the abundance of the major species. The relative CE-SSCP sub-peak background area focuses on minor species and was calculated according to Loisel et al. (2006).

\section{Statistical Analysis}

The fatty acid profiles in the rumen fluids were analyzed by ANOVA, using the General Linear Model of SYSTAT (version 9; SPSS Inc., Chicago, IL), according to the following model:

$$
\mathrm{Y}=\mu+\mathrm{C}+\mathrm{P}+\mathrm{Sd}+\mathrm{Od}+\mathrm{Sd} \times \mathrm{Od}+\varepsilon,
$$

where $\mathrm{Y}$ is the dependent variable; $\mu$ is the mean; $\mathrm{C}, \mathrm{P}$, $\mathrm{Sd}$, and Od are the effects of cow, period, dietary starch level, and sunflower oil addition, respectively; and $\varepsilon$ the residual error.

Fatty acid production or disappearance, efficiencies of BH reactions, Simpson index, and CE-SSCP background area were analyzed according to the following model:

$$
\begin{aligned}
\mathrm{Y}=\mu+\mathrm{C} & +\mathrm{P}+\mathrm{Sd}+\mathrm{Od}+\mathrm{Ss}+\mathrm{FAs}+\mathrm{Sd} \\
\times \mathrm{Od}+\mathrm{Sd} & \times \mathrm{Ss}+\mathrm{Sd} \times \mathrm{FAs}+\mathrm{Od} \times \mathrm{Ss}+\mathrm{Od} \\
& \times \mathrm{FAs}+\mathrm{Ss} \times \mathrm{FAs}+\varepsilon,
\end{aligned}
$$

where Ss and FAs are the effects of starch level and FA source (LnA vs. LeA) in the in vitro substrates, respectively.

Because the initial amounts and balances of LnA, CLnA, and trans-11,cis-15-C18:2 were very low in cultures with added LeA, the statistical analysis of these balances, ELnA, ECLnA, and Et11c15 were only computed on data from LnA-enriched cultures, using the model

$$
\begin{gathered}
\mathrm{Y}=\mu+\mathrm{C}+\mathrm{P}+\mathrm{Sd}+\mathrm{Od}+\mathrm{Ss}+\mathrm{Sd} \times \mathrm{Od} \\
+\mathrm{Sd} \times \mathrm{Ss}+\mathrm{Od} \times \mathrm{Ss}+\varepsilon .
\end{gathered}
$$

Differences were declared significant at $P \leq 0.05$.

The structures of the bacterial communities were analyzed using the StatFingerprints software (Michelland et al., 2009). We compared the communities using the pairwise Euclidean distances of the CE-SSCP profiles. To explore this distance matrix, nonmetric multidimensional scaling (nMDS) was carried out. Pairwise analyses of similarities (ANOSIM) were performed on the distance matrix to test the effect of factors and their interactions. The test is based on the comparison of distances between groups corresponding to factors levels with distances within groups to produce the ANOSIM statistic $R$. The ANOSIM $R$ value indicates the degree of similarity between the groups $(\mathrm{R}>0.75$ : well-separated groups; $0.50<\mathrm{R}<0.75$ : separated but overlapping groups; $0.25<\mathrm{R}<0.50$ : separated but strongly overlapping groups). We only considered effects of factors resulting in an ANOSIM $\mathrm{R}>0.25$.

Additionally, we studied the relationship between some FA balances affected by dietary or incubation conditions and bacterial community. Correlation between the CE-SSCP profiles and FA were tested using redundancy analysis with 10,000 Monte Carlo permutations (Legendre and Legendre, 1998), and Pearson correlation coefficients between the Simpson index and CE-SSCP background area and FA balances were calculated.

\section{RESULTS AND DISCUSSION}

\section{Fatty Acid Profile of Ruminal Fluid from Donor Cows}

As expected, adding oil to the diets of donor cows increased the amount of total FA in the incubates (Table 2). Stearic acid was the major FA, whatever 
the diet of dairy cows, but with a higher percentage when diets contained added oil than without dietary oil. Oil addition increased the proportions of total trans C18:1 but lowered the percentages of polyunsaturated FA. Actually, ruminal fluids were taken before the morning meal (i.e., $15 \mathrm{~h}$ after the previous meal), so that most added unsaturated FA from added oil had been at least isomerized, whereas $\mathrm{BH}$ was less complete when diets did not contain added oil, as unsaturated FA of vegetal cells were not as available for BH as FA of added oil. Increasing the dietary starch level strongly decreased cis-9,trans-11-CLA and trans-11-C18:1 proportions, especially in the high-starch plus oil diet. On the other hand, this diet resulted in the highest trans10,cis-12-CLA and trans-10-C18:1 balances, due to a tendency toward an interaction between starch and oil additions $(P=0.079$ and $P=0.067$ for trans-10,cis-12CLA and trans-10-C18:1, respectively), and the lowest cis-9,trans-11-CLA and trans-11-C18:1 balances. This demonstrates that this combination efficiently resulted in a trans-10 shift.

However, because samples were taken a long time after the meal, the variations of FA composition could fail to accurately reflect the ruminal effects of the diets, so that we will not further discuss these results.

\section{Structure and Diversity of the Bacterial Community}

Increasing dietary starch decreased the Simpson diversity index and the relative CE-SSCP sub-peak background area from 7.6 to 6.6 and from 0.91 to 0.85 , respectively, indicating less numerous but more abundant major bacterial species. Dietary oil, starch level in the incubates, incubated FA, and interactions had no significant effect on the Simpson diversity index and the relative sub-peak background area.
The nonmetric multidimensional scaling (nMDS) plot (Figure 1) of the CE-SSCP profiles of the 5-h in vitro incubations showed that the structure of bacterial communities differed between the high-starch plus oil diet and the 3 other combinations (ANOSIM R $=0.43, P$ $<0.01)$. The starch level in the diets or the incubates, dietary oil, replacement of LeA with LnA and the other interactions between these factors did not modify the structure of the bacterial community. That diversity and structure of the bacterial communities only were affected by dietary starch and its interaction with dietary oil suggests that only the effects of the diet, but not the effects of starch amount and FA nature in the incubates, could have been mediated by a change of microbial population.

\section{Effects of Donor Cow Diet and Starch in the Incubates}

Increasing starch concentration from 21 to $34 \%$ of $\mathrm{DM}$, on average, in the diet of donor cows had no significant effect on ELeA and ELnA (Table 3). Increasing the starch content from 18 to $41 \%$ in culture substrates significantly decreased ELeA from 42.8 to $36.9 \%$, on average. However, this effect significantly interacted with the FA added to the cultures, only affecting cultures with added LnA, which had a low initial LeA amount. This shows that neither starch in the donor cows diet nor starch in the incubates affected the $\mathrm{BH}$ extent of added LeA. Literature data indicate that increasing the proportion of concentrates in the diet decreases the LeA BH extent in vivo (Loor et al., 2004; Glasser et al., 2008; Enjalbert and Troegeler-Meynadier, 2009), ant that a low $\mathrm{pH}$ decreases $\mathrm{BH}$ extent in vitro (Van Nevel and Demeyer, 1996; Troegeler-Meynadier et al., 2003). In our experiment, increasing dietary starch only

Table 2. Amount of total fatty acids (mg/flask) and fatty acid profile (\% of total fatty acids) of ruminal fluids

\begin{tabular}{|c|c|c|c|c|c|c|}
\hline $\begin{array}{l}\text { Cow } \\
\text { diet }^{1}\end{array}$ & $\begin{array}{l}\text { Low } \\
\text { starch }\end{array}$ & $\begin{array}{l}\text { High } \\
\text { starch }\end{array}$ & $\begin{array}{l}\text { Low starch } \\
\quad+\text { oil }\end{array}$ & $\begin{array}{l}\text { High starch } \\
\quad+\text { oil }\end{array}$ & SEM & $\begin{array}{l}\text { Significant } \\
\text { effects }^{2}\end{array}$ \\
\hline $\begin{array}{l}\text { Total FA } \\
\text { FA profile }\end{array}$ & 144.4 & 121.8 & 219.3 & 288.4 & 22.9 & $\mathrm{Od}^{* *}$ \\
\hline C18:0 & 44.48 & 41.97 & 49.57 & 54.62 & 3.15 & $\mathrm{Od}^{*}$ \\
\hline$c 9-\mathrm{C} 18: 1$ & 2.04 & 2.89 & 2.14 & 1.49 & 0.20 & $\mathrm{Od}^{*}, \mathrm{Sd} \times \mathrm{Od}^{*}$ \\
\hline$t 10-\mathrm{C} 18: 1$ & 0.48 & 0.46 & 1.15 & 11.49 & 2.32 & $\mathrm{Od}^{*}$ \\
\hline$t 11-\mathrm{C} 18: 1$ & 3.86 & 4.05 & 13.07 & 1.31 & 0.93 & $\mathrm{Sd}^{* * *}, \mathrm{Od}^{*}, \mathrm{Sd} \times \mathrm{Od}^{* * *}$ \\
\hline Total $t$ C18:1 & 7.62 & 6.78 & 19.95 & 17.15 & 2.58 & $\mathrm{Od}^{* *}$ \\
\hline LeA & 3.61 & 5.15 & 1.71 & 2.90 & 0.51 & $\mathrm{Sd}^{*}, \mathrm{Od}^{* *}$ \\
\hline$t 10, c 12$-CLA & 0.02 & 0.01 & 0.02 & 0.03 & 0.01 & $\mathrm{Od}^{*}$ \\
\hline$c 9, t 11-\mathrm{CLA}$ & 0.06 & 0.04 & 0.18 & 0.01 & 0.02 & $\mathrm{Sd}^{* *}, \mathrm{Sd} \times \mathrm{Od}^{* *}$ \\
\hline t9,t11-CLA & 0.35 & 0.20 & 0.20 & 0.10 & 0.07 & \\
\hline LnA & 0.79 & 0.32 & 0.27 & 0.27 & 0.13 & \\
\hline CLnA & 0.045 & 0.016 & 0.023 & 0.005 & 0.007 & $\mathrm{Sd}^{* *}, \mathrm{Od}^{*}$ \\
\hline
\end{tabular}

${ }^{1} \mathrm{FA}=$ fatty acids; $c=$ cis $;=$ trans $;$ LeA $=$ linoleic acid CLA $=$ conjugated linoleic acid $;$ LnA $=\alpha$-linolenic acid; CLnA = cis-9,trans-11, cis-15 conjugated linolenic acid.

${ }^{2} \mathrm{Od}=$ dietary oil addition; $\mathrm{Sd}=$ dietary starch level; $\times$ indicates an interaction.

${ }^{*} P<0.05 ; * * P<0.01 ;{ }^{* * *} P<0.001$. 


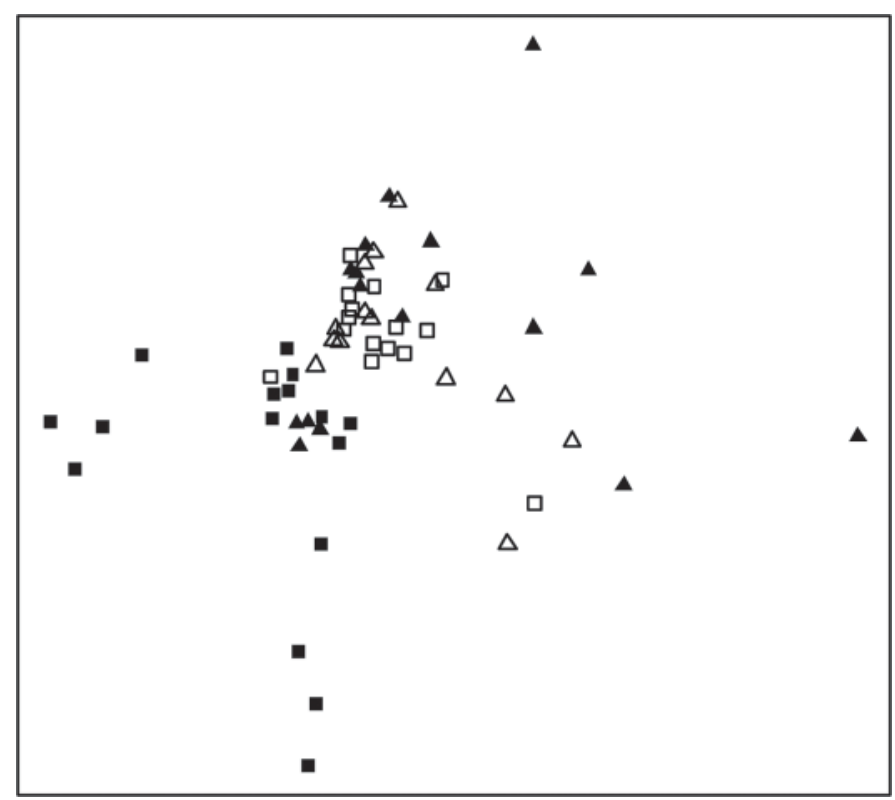

Figure 1. Nonmetric multidimensional scaling plot (nMDS) of the capillary electrophoresis single-strand conformation polymorphism (CE-SSCP) profiles of 5-h in vitro cultures. The marks relate to the diets of donor cows: low starch without sunflower oil $(\Delta)$, low starch with sunflower oil $(\square)$, high starch without sunflower oil $(\mathbf{\Lambda})$, and high starch with sunflower oil (ם).

decreased the final $\mathrm{pH}$ by 0.1 and increasing starch in substrates decreased ruminal $\mathrm{pH}$ by 0.3 (results not shown). A $0.3 \mathrm{pH}$ unit decrease has already been shown to decrease ELeA disappearance (Van Nevel and Demeyer, 1996). These authors also showed that lipolysis is much more sensitive to low $\mathrm{pH}$ values than isomerization. In our experiment, in cultures with added LeA, most LeA was in a free form, so that its isomerization could not be precluded by a slow lipolysis. This could explain the lack of negative effect of starch level on ELeA.

A small effect of concentrates and $\mathrm{pH}$ on isomerization compared with lipolysis could also explain why, in our cultures with added LnA, increasing starch in the substrates did not negatively affect ELnA, as most LnA originated from added free LnA. Increasing the starch level in the substrate even increased ELnA by $10 \%$; to our knowledge, no other published experiment has investigated the effect of starch level on the in vitro isomerization of free $\mathrm{LnA}$.

High-starch diets slightly increased ECLA and ECLnA, resulting in a decreased CLnA balance (Table 4). Starch addition to the substrates did not affect ECLA but increased ECLnA, resulting in a decreased CLnA balance. Although statistically significant, these effects remained in a narrow range, as ECLA and ECLnA were near $90 \%$, whatever the diet of the donor cow or the incubation substrate. The reduction of CLA is

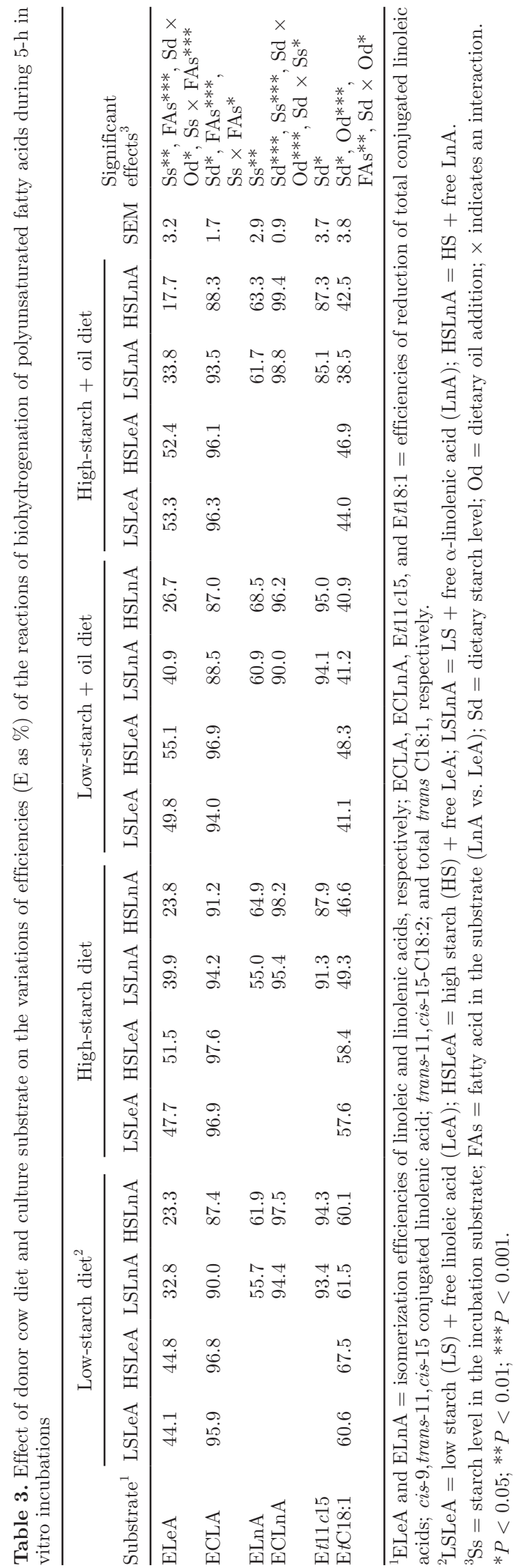

Journal of Dairy Science Vol. 94 No. 11, 2011 
known to be very efficient even at low $\mathrm{pH}$ (TroegelerMeynadier et al., 2006), which explains the very limited effect of starch in our experiment.

Starch addition to the diet decreased Et11c15 from 94 to $88 \%$ and Et18:1 from 53 to $48 \%$, on average (Table 3), resulting in increased trans-11,cis-15-C18:2 and trans C18:1 balances (Table 4), but starch addition to the incubates did not affect Et $11 c 15$ and Et18:1. An increased duodenal flow of trans C18:1 has already been observed when increasing dietary concentrate, and buffer addition alleviated this effect, suggesting that ruminal $\mathrm{pH}$ played a major role in this accumulation (Kalscheur et al., 1997). In our experiment, donor cows receiving the high-starch diets did not receive a buffer, so that a starch effect on the ruminal $\mathrm{pH}$ and, consequently, the microflora could be expected, affecting $\mathrm{E} t 11 c 15$ and $\mathrm{E} t 18: 1$ in vitro. On the other hand, the 0.3 final $\mathrm{pH}$ difference due to starch addition to the incubates could have failed to affect these efficiencies.

Oil addition to the diets marginally increased ELeA from 39 to $41 \%$ and did not affect ECLA, ELnA, ECLnA, and $\mathrm{E} t 11 c 15$. On the other hand, Et18:1 decreased from 58 to $43 \%$, on average, when oil was added to the diets. Troegeler-Meynadier et al. (2006) previously reported that this BH reaction is easily saturated. Shingfield et al. (2008) observed an increased proportion of trans C18:1 among omasal FA when increasing dietary sunflower oil in the diet of lactating dairy cows, and modeling data from several in vivo experiments, Moate et al. (2004) established that the $\mathrm{BH}$ rate of trans $\mathrm{C} 18: 1$ is negatively affected by the concentration of free FA in the rumen. Moreover, Lourenço et al. (2010) showed that Butyrivibrio proteoclasticus, which is the main bacteria responsible of this last reduction (Wallace et al., 2006), is more sensitive to unsaturated FA than $B$. fibrisolvens which is the main bacteria responsible for the previous BH steps. In spite of this negative effect on Et18:1, oil addition to the diets decreased the in vitro balances of most trans $\mathrm{C} 18: 1 \mathrm{BH}$ intermediates, which could be due to the higher initial proportions of trans C18:1 (Table 2).

Taken together, our results relative to the effects of starch and oil addition to the diets of donor cows suggest that the last $\mathrm{BH}$ reduction was inhibited by either high-starch or oil-supplemented diets. The effect of dietary starch on Et18:1 interacted with dietary oil, being observed only when the diets did not contain added oil. This shows that starch and oil additions had no additive effect, as increasing the dietary starch level did not lower trans-C18:1 reduction when this reduction was already inhibited by oil addition to the diet, suggesting that they affected the same target.

The main isomer-specific effect of high-starch diets was observed on the equilibrium between trans-10- and trans-11 isomers in incubates (Table 4). High-starch diets decreased the cis-9,trans-11-CLA balance by 2.3 times, increased the trans-10, cis-12-C18:2 and trans10-C18:1 balances by 2.2 and 1.8 times, respectively, but did not affect the trans-11-C18:1 balance. The effect of the starch content or forage-to-concentrate ratio of the production of trans-10-isomers in fat-supplemented diets has been previously observed in vivo with diets without (Piperova et al., 2002) or with (Loor et al., 2004) added fat. In vitro, Choi et al. (2005) reported that, whatever the culture $\mathrm{pH}$, in vitro cultures contained more trans-10, cis-12-C18:2 when the donor cow received a high-concentrate diet.

As discussed later, we did not observe a trans-10 shift in LnA incubates; thus, we studied the relationship between trans-10 isomer (trans-10,cis-12-C18:2 + trans10-C18:1) balance and bacterial community only on LeA incubates. Redundancy analysis showed that total trans-10 isomers balance explained $11 \%(P=0.005)$ of the total inertia of CE-SSCP profiles. This is consistent with the results of Weimer et al. (2010) who observed that the bacterial community was affected in cows experiencing milk fat depression, usually associated with a trans-10 shift. In our experiment, with the same data set of LeA incubates, trans-10 isomer balance did not significantly correlate with the Simpson index and the CE-SSCP background area $(\mathrm{r}=0.33, P=0.069$ and $\mathrm{r}$ $=0.23, P=0.21$, respectively).

Dietary starch interacted with dietary oil for cis9,trans-11-CLA, trans-10,cis-12-CLA, and trans11-C18:1 balances: the increase of trans-10, cis-12-CLA due to dietary starch addition was higher when the diets contained sunflower oil, and high-starch diets decreased the balance of trans-11 isomers only when oil was added to the diets, resulting in the highest trans-10, cis-12-CLA and lowest trans-11 isomer balances when donor cows received the high-starch plus oil diet (Table 4). This reveals a clear shift from the trans-11 to the trans-10 BH pathway. These changes could have been driven by the strong changes of bacterial community structure observed with the high-starch plus oil diet. Griinari et al. (1998), studying the effect of concentrate level and unsaturation level of dietary fat found a trend toward a similar interaction, with a strong decrease in trans-11-C18:1 in milk fat when increasing the concentrate level in diets containing unsaturated fat carried out by corn oil. Additionally, they described a significant interaction between dietary concentrate and unsaturated fat for milk trans-10-C18:1, the highest levels being observed with high-concentrate diets containing unsaturated fat. In our experiment, the trend toward this interaction could be observed on the ruminal fluid of donor cows (Table 2) but was not observed on in vitro balances: as discussed later, the 
Table 4. Effect of donor cow diet and culture substrate on the variations of fatty acids profile (\% of total fatty acids) during 5-h in vitro incubations

\begin{tabular}{|c|c|c|c|c|c|c|c|c|c|c|c|c|c|c|c|c|c|c|}
\hline \multirow[b]{2}{*}{ Substrate $^{1}$} & \multicolumn{4}{|c|}{ Low-starch $\operatorname{diet}^{2}$} & \multicolumn{4}{|c|}{ High-starch diet } & \multicolumn{4}{|c|}{ Low-starch + oil diet } & \multicolumn{4}{|c|}{ High-starch + oil diet } & \multirow[b]{2}{*}{ SEM } & \multirow{2}{*}{$\begin{array}{l}\text { Significant } \\
\text { effects }^{3}\end{array}$} \\
\hline & LSLeA & HSLeA & LSLnA & HSLnA & LSLeA & HSLeA & LSLnA & HSLnA & LSLeA & HSLeA & LSLnA & HSLnA & LSLeA & HSLeA & LSLnA & HSLnA & & \\
\hline C18:0 & 9.9 & 10.2 & 9.3 & 8.0 & 11.2 & 10.9 & 7.2 & 4.6 & 9.4 & 10.6 & 8.9 & 7.8 & 9.1 & 9.0 & 6.5 & 6.7 & 1.3 & $\mathrm{FAs}^{* * *}$ \\
\hline$c 9-\mathrm{C} 18: 1$ & -0.43 & 0.28 & 0.68 & 0.24 & -1.01 & -0.51 & -1.06 & -1.91 & -0.81 & -0.41 & -0.78 & -0.26 & -0.66 & -0.39 & -1.13 & -0.80 & 0.35 & $\begin{array}{l}\mathrm{Sd}^{* * *}, \mathrm{Sd} \times \mathrm{Od}^{* *} \\
\mathrm{Sd} \times \mathrm{FAs}^{*}\end{array}$ \\
\hline$c 11-\mathrm{C} 18: 1$ & 0.12 & 0.19 & 0.14 & 0.26 & 0.10 & 0.29 & 0.18 & 0.39 & 0.07 & 0.13 & 0.08 & 0.19 & 0.09 & 0.24 & 0.11 & 0.26 & 0.03 & $\begin{array}{l}\mathrm{Sd}^{* * *}, \mathrm{Od}^{* * *}, \mathrm{Ss}^{* * *}, \\
\mathrm{FAs}^{* *}, \mathrm{Sd} \times \mathrm{Ss}^{* *}\end{array}$ \\
\hline c12-C18:1 & 0.38 & 0.39 & 0.24 & 0.42 & 0.51 & 0.95 & 0.41 & 0.64 & 0.15 & 0.19 & 0.08 & 0.17 & 0.27 & 0.24 & 0.19 & 0.17 & 0.08 & $\begin{array}{l}\mathrm{Sd}^{* * *}, \mathrm{Od}^{* * *}, \\
\mathrm{Ss}^{* *}, \mathrm{FAs}^{*}, \mathrm{Sd} \times \\
\mathrm{Od}^{*}, \mathrm{Od} \times \mathrm{Ss}^{*}\end{array}$ \\
\hline$c 15-\mathrm{C} 18: 1$ & 0.02 & 0.02 & 0.41 & 0.58 & 0.04 & 0.04 & 0.61 & 0.68 & 0.01 & 0.02 & 0.17 & 0.30 & 0.00 & 0.00 & 0.69 & 0.61 & 0.07 & $\begin{array}{l}\mathrm{Sd}^{* * *}, \mathrm{Od}^{*}, \mathrm{FAs}^{* * *}, \\
\mathrm{Sd} \times \mathrm{FAs}^{* * *}\end{array}$ \\
\hline$t 5-\mathrm{C} 18: 1$ & 0.02 & 0.02 & 0.02 & 0.02 & 0.03 & 0.04 & 0.01 & 0.02 & 0.01 & 0.01 & 0.01 & 0.01 & -0.01 & -0.02 & $2-0.02$ & -0.03 & 0.01 & $\begin{array}{l}\mathrm{Sd}^{* * *}, \mathrm{Od}^{* * *} \\
\mathrm{FAs}^{*}, \mathrm{Sd} \times \mathrm{Od}^{* * *}\end{array}$ \\
\hline $\begin{array}{l}t 6+t 7+ \\
t 8-\mathrm{C} 18: 1\end{array}$ & 0.27 & 0.28 & 0.26 & 0.28 & 0.37 & 0.56 & 0.33 & 0.37 & 0.18 & 0.22 & 0.19 & 0.28 & 0.12 & 0.07 & 0.06 & 0.02 & 0.05 & $\begin{array}{l}\mathrm{Od}^{* * *}, \mathrm{Sd} \times \\
\mathrm{Od}^{* * *}, \mathrm{Sd} \times \mathrm{FAs}^{*}\end{array}$ \\
\hline t9-C18:1 & 0.15 & 0.14 & 0.14 & 0.17 & 0.22 & 0.32 & 0.21 & 0.24 & 0.11 & 0.14 & 0.11 & 0.18 & 0.10 & 0.06 & 0.05 & 0.04 & 0.03 & $\mathrm{Od}^{* * *}, \mathrm{Sd} \times \mathrm{Od}^{* * *}$ \\
\hline$t 10-\mathrm{C} 18: 1$ & 0.88 & 1.05 & 0.38 & 0.52 & 1.24 & 2.26 & 0.58 & 0.97 & 0.58 & 0.78 & 0.29 & 0.53 & 1.39 & 2.25 & 0.33 & -0.18 & 0.27 & $\begin{array}{l}\mathrm{Sd}^{* * *}, \mathrm{Ss}^{*}, \mathrm{FAs}^{* * *}, \\
\mathrm{Sd} \times \mathrm{FAs}^{* * *}\end{array}$ \\
\hline$t 11-\mathrm{C} 18: 1$ & 1.93 & 1.23 & 2.03 & 1.90 & 2.67 & 2.34 & 3.44 & 4.34 & 1.90 & 1.20 & 1.42 & 2.09 & 1.05 & 0.25 & 0.46 & 0.34 & 0.33 & $\begin{array}{l}\mathrm{Od}^{* * *}, \mathrm{FAs}^{*}, \mathrm{Sd} \\
\times \mathrm{Od}^{* * *}, \mathrm{Od} \times \\
\mathrm{FAs}^{* *}, \mathrm{Ss} \times \mathrm{FAs}^{* *}\end{array}$ \\
\hline$t 12-\mathrm{C} 18: 1$ & 0.38 & 0.37 & 0.47 & 0.56 & 0.54 & 0.73 & 0.61 & 0.49 & 0.21 & 0.27 & 0.30 & 0.40 & 0.18 & 0.07 & 0.22 & 0.21 & 0.07 & $\mathrm{Od}^{* * *}, \mathrm{Sd} \times \mathrm{Od}^{* * *}$ \\
\hline$t 13+\mathrm{t} 14-\mathrm{C} 18: 1$ & 0.18 & -0.16 & 0.41 & 1.94 & 0.91 & 1.02 & 2.66 & 3.42 & 0.35 & 0.39 & 1.07 & 1.66 & 0.34 & 0.19 & 1.88 & 1.73 & 0.37 & $\begin{array}{l}\mathrm{Sd}^{* * *}, \mathrm{FAs}^{* * *}, \mathrm{Sd} \\
\times \mathrm{Od}^{* *}, \mathrm{Ss} \times \mathrm{FAs}^{*}\end{array}$ \\
\hline$t 15-\mathrm{C} 18: 1$ & 0.21 & 0.16 & 0.75 & 0.91 & 0.35 & 0.34 & 0.72 & 0.65 & 0.13 & 0.13 & 0.49 & 0.56 & 0.12 & 0.04 & 0.67 & 0.59 & 0.13 & $\mathrm{Od}^{*}, \mathrm{FAs}^{* * *}$ \\
\hline$t 16-\mathrm{C} 18: 1$ & 0.25 & 0.24 & 0.61 & 0.66 & 0.35 & 0.34 & 0.54 & 0.35 & 0.16 & 0.20 & 0.48 & 0.50 & 0.12 & 0.09 & 0.45 & 0.40 & 0.08 & $\mathrm{Od}^{* *}, \mathrm{FAs}^{* * *}$ \\
\hline Total $t$ C18:1 & 4.2 & 3.3 & 5.0 & 6.9 & 6.6 & 7.9 & 9.0 & 10.8 & 3.6 & 3.3 & 4.3 & 6.2 & 3.3 & 2.9 & 4.0 & 3.0 & 0.8 & $\begin{array}{l}\mathrm{Sd}^{* *}, \mathrm{Od}^{* * *}, \\
\mathrm{FAs}^{* * *}, \mathrm{Sd} \times \mathrm{Od}^{* * *}\end{array}$ \\
\hline LeA & -18.7 & -19.7 & -2.7 & -2.2 & -21.2 & -23.8 & -3.6 & -2.4 & -15.7 & -17.9 & -2.4 & -1.6 & -14.8 & -14.9 & -2.0 & -1.1 & 1.1 & $\begin{array}{l}\mathrm{Od}^{* * *}, \mathrm{Lns}^{* * *}, \\
\mathrm{Sd} \times \mathrm{Od}^{* *}, \mathrm{Od} \times\end{array}$ \\
\hline$t 10, c 12-\mathrm{CLA}$ & 0.17 & 0.20 & 0.01 & 0.01 & 0.18 & 0.26 & 0.02 & 0.04 & 0.10 & 0.09 & 0.01 & 0.01 & 0.38 & 0.41 & 0.02 & 0.02 & 0.04 & $\begin{array}{l}\mathrm{Sd}^{* * *}, \mathrm{FAs}^{* * *}, \mathrm{Sd} \times \\
\mathrm{Od}^{* *}, \mathrm{Sd} \times \mathrm{FAs}^{* * *}\end{array}$ \\
\hline$c 9, t 11-\mathrm{CLA}$ & 0.33 & 0.13 & 0.06 & 0.02 & 0.30 & 0.10 & 0.07 & 0.04 & 0.52 & 0.21 & 0.05 & 0.02 & 0.05 & 0.02 & 0.01 & 0.00 & 0.04 & $\begin{array}{l}\mathrm{Sd}^{* * *}, \mathrm{Ss}^{* * *} \\
\mathrm{FAs}^{* * *}, \mathrm{Sd} \times \\
\mathrm{Od}^{* * *} \mathrm{Sd} \times \mathrm{FAs}^{* * *}, \\
\mathrm{Ss} \times \mathrm{FAs}^{* * *}\end{array}$ \\
\hline t9,t11-CLA & 0.05 & 0.02 & -0.01 & 0.00 & 0.05 & 0.08 & 0.01 & 0.01 & 0.07 & -0.01 & -0.01 & -0.04 & 0.01 & 0.04 & 0.00 & 0.00 & 0.03 & $\mathrm{FAs}^{* *}$ \\
\hline$t 11, t 13-\mathrm{CLA}$ & 0.02 & 0.02 & 0.27 & 0.39 & 0.02 & 0.02 & 0.36 & 0.67 & 0.00 & 0.01 & 0.08 & 0.10 & 0.01 & 0.00 & 0.22 & 0.19 & 0.05 & $\begin{array}{l}\mathrm{Sd}^{* *}, \mathrm{Od}^{* * *} \\
\mathrm{Lns}^{* * *}, \mathrm{Sd} \times \mathrm{Lns}^{* *}, \\
\mathrm{Od} \times \mathrm{Ss}^{*}, \mathrm{Od} \times \\
\mathrm{Lns}^{* * *}, \mathrm{Ss} \times \mathrm{Lns}^{*}\end{array}$ \\
\hline Total-CLA & 0.54 & 0.35 & 0.06 & 0.03 & 0.53 & 0.44 & 0.09 & 0.09 & 0.69 & 0.30 & 0.05 & -0.01 & 0.44 & 0.47 & 0.04 & 0.02 & 0.05 & $\begin{array}{l}\mathrm{Ss}^{* *}, \mathrm{FAs}^{* * *}, \mathrm{Sd} \\
\times \mathrm{Ss}^{*}, \mathrm{Ss} \times \mathrm{FAs}^{*}\end{array}$ \\
\hline$t 11, c 15-\mathrm{C} 18: 2$ & & & 1.01 & 1.09 & & & 1.63 & 2.78 & & & 0.79 & 0.86 & & & 2.02 & 1.77 & 0.52 & $\mathrm{Sd}^{* *}$ \\
\hline $\operatorname{Ln} A$ & & & -19.8 & -22.3 & & & -20.0 & -24.1 & & & -16.0 & -18.4 & & & -13.7 & -14.3 & 1.5 & $\mathrm{Od}^{* * *}, \mathrm{Ss}^{*}$ \\
\hline CLnA & & & 1.08 & $\quad 0.48$ & & & 0.91 & 0.42 & & & 1.58 & 0.65 & & & 0.17 & 0.08 & 0.14 & $\begin{array}{l}\mathrm{Sd}^{* * *}, \mathrm{Ss}^{* * *}, \mathrm{Sd} \times \\
\mathrm{Od}^{* * *}, \mathrm{Sd} \times \mathrm{Ss}^{*}\end{array}$ \\
\hline
\end{tabular}


production of trans-10-C18:1 in cultures incubated with LnA was low, which could have masked the effects on LeA of a trans-10-producing ruminal microflora.

Similar to high-starch diets, high-starch substrates decreased the cis-9,trans-11-CLA balance, which was numerically but not statistically observed by Fuentes et al. (2009), and increased the trans-10-C18:1 balance, whereas Fuentes et al. (2009) observed an opposite effect. Unlike dietary starch, increasing the starch content of substrates had no significant effect on trans-10,cis12-CLA and trans-11-C18:1 balances.

Among $\mathrm{BH}$ intermediates that mainly result from LnA BH, high-starch diets strongly increased trans11,cis-15-C18:2; trans-11,trans-13-CLA; and trans-13 + trans-14-C18:1. The high-starch substrates numerically increased trans-11,trans-13-CLA and trans-13+ trans-14-C18:1 balances $(P=0.052$ and $P=0.109$, respectively), which is consistent with the in vivo results of Loor et al. (2004). Increasing starch in the diets also increased cis-11, cis-12, and cis-15-C18:1 balances.

\section{Effects of the Incubated Fatty Acid and Interactions with Starch in Diets and Substrates}

On average, ELeA was $50 \%$ in the cultures with added LeA but only $30 \%$ in the cultures with added LnA (Table 3 ). In vitro, LnA addition has already been shown to inhibit LeA isomerization (Troegeler-Meynadier et al., 2003), which, at least in part, explains this very low LeA BH in our cultures with added LnA. In our experiment, most LeA in the cultures with added LeA was the pure free LeA added to the medium, whereas in the cultures with added LnA, the LeA originated from the ruminal fluid and the forage and concentrates used as a substrate, in an acylglycerol form, needing digestion of the vegetal structures and lipolysis before $\mathrm{BH}$.

On average, ELnA was $61 \%$ in cultures with LnA, compared with $50 \%$ for ELeA in cultures with LeA (Table 3). This higher BH extent of LnA compared with LeA is consistent with literature data (Enjalbert and Troegeler-Meynadier, 2009). However, in our experiment, this higher extent of LnA than LeA BH was not necessarily due to the nature of the FA, but could also be due to different physical forms: $97 \%$ of LnA in cultures with added LnA originated from pure added LnA, compared with $79 \%$ of LeA originating from pure LeA in cultures with added LeA.

Adding LnA resulted in a 10 times lower increase in total CLA proportion than LeA addition (0.05 and $0.47 \%$, on average, respectively), but resulted in high CLnA and trans-11,cis-15-C18:2 balances (Table 4), which is consistent with the present knowledge relative to LeA and $\mathrm{LnA} \mathrm{BH}$. Incubation of $\mathrm{LnA}$ resulted in a trans-11,cis-15-C18:2 balance that was 44 times greater than the cis9,trans-11-CLA balance, which is similar to the 47 ratio observed by Loor et al. (2004) in vivo when supplementing diets with linseed oil. On the contrary, incubation with added LeA resulted in negligible balances of CLnA, trans-11,trans-13-CLA and trans-11,cis-15-C18:2 (results not shown), but increased trans-10,cis-12-; cis-9,trans-11-; and trans9,trans-11-CLA balances.

During incubations, the percentage of total trans C18:1 increased by $4.4 \%$, on average, in cultures with added LeA compared with $6.2 \%$ in cultures with $\mathrm{LnA}$, in relation to a higher Et18:1 than in cultures with LnA. The reduction of trans-C18:1 to C18:0 is inhibited in vitro by an LeA concentration over $1 \mathrm{mg} / \mathrm{mL}$ (Harfoot et al., 1973), and Troegeler-Meynadier et al. (2006) demonstrated that this effect was due to a saturation of the reduction when the concentration of trans $\mathrm{C} 18: 1$ was high. A similar effect can be expected when LnA is incubated, as LnA BH also produces trans $\mathrm{C} 18: 1$, but an inhibition of the last reduction by other LnA BH intermediates, or different inhibiting effects of different trans C18:1 isomers could have resulted in this lower Et18:1 with LnA than with LeA.

Compared with cultures with LeA, cultures with LnA had a quite different distribution of octadecenoic $\mathrm{BH}$ intermediates. Incubation of $\mathrm{LnA}$ instead of LeA increased the balances of cis-11-, cis-15-, trans-11-, trans-13 + trans-14-, trans-15-, and trans-16-C18:1; tended to increase the balance of trans-12-C18:1 $(P=$ 0.092); and decreased the balances of cis-12-, trans-5-, and trans-10-C18:1. Most of these changes are consistent with the present knowledge on LeA and LnA $\mathrm{BH}$, the latter being, in particular, known to result in cis-15-, trans-13 + trans-14-, trans-15-, and trans-16isomers (Kemp and Lander, 1984; Jouany et al., 2007).

Destaillats et al. (2005) proposed a biohydrogenation pathway of LnA where LnA was, in part, isomerized to cis-9,trans-13, cis-15-C18:3, whose reductions produced trans-13-C18:1. Whatever the diets of cows and the incubation substrates, we did not find cis-9,trans13, cis-15-C18:3, even in samples with high trans-13+ trans-14-C18:1 balances.

Formation of trans-10 isomers during LeA and LnA $\mathrm{BH}$ have been proposed by Griinari and Bauman (1999). This production from LeA has been clearly demonstrated in vivo with a corn oil-supplemented diet (Griinari et al., 1998), and in in vitro ruminal cultures with added LeA (Troegeler-Meynadier et al., 2003; Jouany et al., 2007). In the pathway proposed by Griinari and Bauman (1999), LnA could be hydrogenated via the trans-10 pathway instead of the more classical trans-11 pathway with trans-10,cis-12,cis-15-C18:3 and trans-10, cis-15-C18:2 as intermediates. As far as we are aware, only Kemp et al. (1975) reported traces of this 

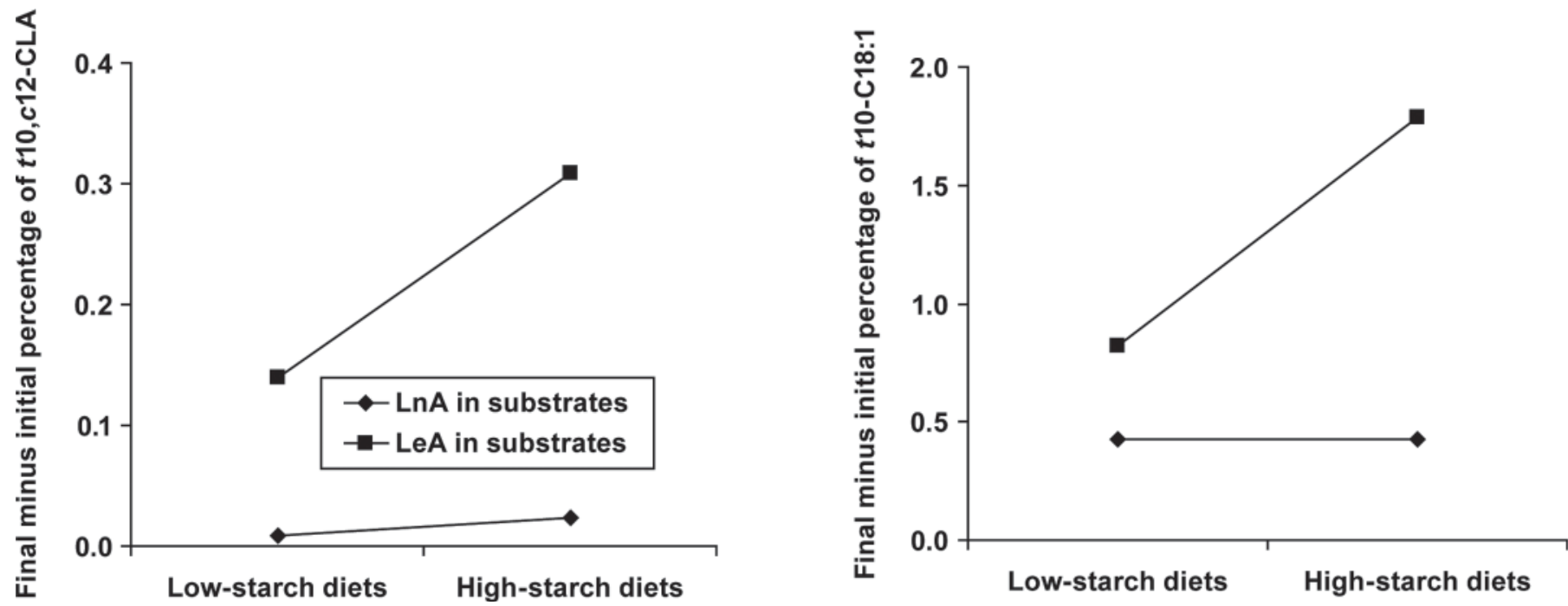

Figure 2. Effects of interaction between dietary starch level and the incubated fatty acid on the balances of trans-10,cis-12-conjugated linoleic acid $(t 10, c 12$-CLA) and trans-10-C18:1 in 5-h in vitro cultures. LnA = linolenic acid; LeA = linoleic acid.

latter isomer to be produced by a strain of ruminal bacteria. The trans-10,cis-12,cis-15-C18:3 isomer has been isolated in ewe cheese (Winkler and Steinhart, 2001), but it could result from a microbial isomerization of LnA or cis-9,trans-11,cis-15 CLnA in milk or cheese.

Increasing dietary starch strongly increased trans10, cis-12-CLA and trans-10-C18:1 when LeA was incubated, but not when LnA was incubated (Figure 2). Using a high-concentrate diet, Loor et al. (2005) also observed 6.3 and 3.8 times lower proportions of trans10,cis-12-CLA and trans-10-C18:1, respectively, in the duodenal flow of cows supplemented with linseed oil, whose main FA is LnA, compared with cows supplemented with sunflower oil, whose main FA is LeA.
Similarly, incubated starch interacted with incubated FA for trans-11-C18:1 and trans-13 + trans-14-C18:1 balances and a trend toward this interaction was observed for trans-10-C18:1 balance $(P=0.073)$. Actually, in cultures with LeA, increasing starch level in the substrate increased the trans-10-C18:1 balance by $55 \%$ but decreased the trans-11-C18:1 balance by $34 \%$, clearly showing a shift in BH pathway (Figure 3). On the contrary, in cultures with LnA, increasing starch increased trans-10, trans-11, and trans-13 + trans14-C18:1 balances by 15,18 , and $45 \%$, respectively, showing no major shift in BH pathway.

This lack of trans-10 shift in cultures with LnA, whatever the starch content of the diets or the incubation
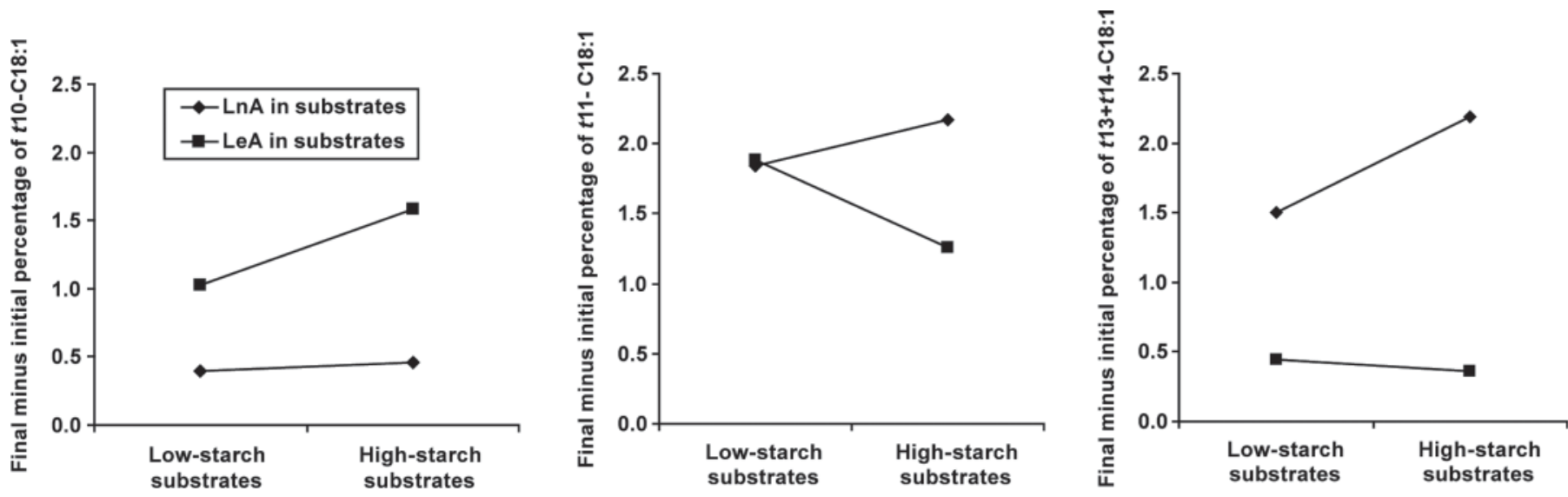

Figure 3. Effects of interaction between starch level in the incubation substrate and the incubated fatty acid on the balances of trans10-C18:1, trans-11-C18:1, and trans-13 + trans-14-C18:1 in 5-h in vitro cultures. LnA = linolenic acid; LeA = linoleic acid. 
substrates, strongly suggests that LnA BH does not produce trans-10 isomers. Moreover, the lack of effect of dietary starch on the isomeric profile of $\mathrm{BH}$ intermediates with LnA incubation, as opposed to the shift toward trans-10 isomers with LeA incubation, suggests that dietary conditions that result in a trans-10 shift of LeA BH do not produce this shift in LnA BH. This trans-10 shift has been described with high-starch diets without added fat (Griinari et al., 1998), with added sunflower oil (Roy et al., 2006), and also with diets supplemented with linseed oil (Loor et al., 2004; Pottier et al., 2006). However, LeA respectively represented 20 and $36 \%$ of total dietary FA in these experiments, making it impossible to ascertain what FA trans-10 isomers originated from.

That the incubated FA did not affect the structure and diversity of the bacterial community suggests that the differences of $\mathrm{BH}$ pathways between LeA and LnA observed in our incubations did not relate to differences of microbiota, but only to differences of BH substrate.

\section{CONCLUSIONS}

The high-starch plus oil diet resulted in a trans-10 shift of LeA BH in donor cows. This shift was also observed in vitro when ruminal fluids from cows receiving the high-starch plus oil diet were incubated with LeA, and it related to a change of structure of the bacterial community. Increasing the starch level in the incubates also increased the trans-10-C18:1 balance. On the contrary, no trans-10 shift was observed when LnA was incubated with the rumen fluid from cows receiving this high-starch plus oil diet or when incubated with high-starch substrate. Because LeA and LnA incubations resulted in similar bacterial communities at the end of the incubations, differences of $\mathrm{BH}$ pathways between these $2 \mathrm{FA}$ when incubated with ruminal fluid from cows exhibiting a trans-10 shift are intrinsic to the nature of FA.

\section{ACKNOWLEDGMENTS}

The authors thank M. L. Chemit and the staff at the experimental station [Unité Mixte de Recherche (UMR) 1289 Tandem, INRA, Castanet-Tolosan, France]. The work of the staff at the Centre de Ressources, Génotypage et Séquencage of Toulouse (France) is gratefully acknowledged.

\section{REFERENCES}

Akraim, F., M. C. Nicot, P. Juaneda, and F. Enjalbert. 2007. Conjugated linolenic acid (CLnA), conjugated linoleic acid (CLA) and other biohydrogenation intermediates in plasma and milk fat of cows fed raw or extruded linseed. Animal 1:835-843.
Baumgard, L. H., J. K. Sangster, and D. E. Bauman. 2001. Milk fat synthesis in dairy cows is progressively reduced by increasing amounts of trans-10,cis-12 conjugated linoleic acid. J. Nutr. 131:1764-1769.

Choi, N.-J., J. Y. Imm, S. Oh, B.-C. Kim, H.-J. Hwang, and Y. J. Kim. 2005. Effect of $\mathrm{pH}$ and oxygen on conjugated linoleic acid (CLA) production by mixed rumen bacteria from cows fed high concentrate and high forage diets. Anim. Feed Sci. Technol. 123124:643-653.

Destaillats, F., J. P. Trottier, J. M. G. Galvez, and P. Angers. 2005. Analysis of $\alpha$-linolenic acid biohydrogenation intermediates in milk fat with emphasis on conjugated linolenic acids. J. Dairy Sci. 88:3231-3239

Enjalbert, F., and A. Troegeler-Meynadier. 2009. Biosynthesis of trans fatty acids in ruminants. Pages $1-31$ in Trans Fatty Acids in Human Nutrition. F. Destaillats, J.-L. Sébédio, F. Dionisi, and J. M. Chardigny, ed. The Oily Press, Bridgwater, UK.

Fuentes, M. C., S. Calsamiglia, W. Cardozo, and B. Vlaeminck. 2009. Effect of $\mathrm{pH}$ and level of concentrate in the diet on the production of biohydrogenation intermediates in a dual-flow continuous culture. J. Dairy Sci. 92:4456-4466.

Gervais, R., and P. Y. Chouinard. 2008. Effects of intravenous infusion of conjugated diene C18:3 isomers on milk fat synthesis in lactating dairy cows. J. Dairy Sci. 91:3568-3578.

Glasser, F., P. Schmidely, D. Sauvant, and M. Doreau. 2008. Digestion of fatty acids in ruminants: A meta-analysis of flows and variation factors: 2. C18 fatty acids. Animal 2:691-704.

Griinari, J. M., and D. E. Bauman. 1999. Biosynthesis of conjugated linoleic acid. Pages 180-200 in Advances in Conjugated Linoleic Acid Research, Vol. 1. M. P. Yurawecz, M. M. Mossoba, J. K. G. Kramer, M. W. Pariza, and G. J. Nelson, ed. AOCS Press, Champaign, IL.

Griinari, J. M., B. A. Corl, S. H. Lacy, P. Y. Chouinard, K. V. V. Nurmela, and D. E. Bauman. 2000. Conjugated linoleic acid is synthesized endogenously in lactating dairy cows by $\Delta^{9}$-desaturase. J. Nutr. 130:2285-2291.

Griinari, J. M., D. A. Dwyer, M. A. McGuire, D. E. Bauman, D. L. Palmquist, and K. V. Nurmela. 1998. Trans-octadecenoic acids and milk fat depression in lactating dairy cows. J. Dairy Sci. 81:1251-1261.

Harfoot, C. G., R. C. Noble, and J. H. Moore. 1973. Factors influencing the extent of biohydrogenation of linoleic acid by rumen microorganisms in vitro. J. Sci. Food Agric. 24:961-970.

Ip, M. M., S. O. McGee, P. A. Masso-Welch, C. Ip, X. Meng, L. Ou, and S. F. Shoemaker. 2007. The $t 10, c 12$ isomer of conjugated linoleic acid stimulates mammary tumorigenesis in transgenic mice over-expressing erbB2 in the mammary epithelium. Carcinogenesis 28:1269-1276.

Jouany, J. P., B. Lassalas, M. Doreau, and F. Glasser. 2007. Dynamic features of the rumen metabolism of linoleic acid, linolenic acid and linseed oil measured in vitro. Lipids 42:351-360.

Kalscheur, K. F., B. B. Teter, L. S. Piperova, and R. A. Erdman. 1997. Effect of dietary forage concentration and buffer addition on duodenal flow of trans-C18:1 fatty acids and milk fat production in dairy cows. J. Dairy Sci. 80:2104-2114.

Kemp, P., and D. J. Lander. 1984. Hydrogenation in vitro of $\alpha$-linolenic acid to stearic acid by mixed cultures of pure strains of rumen bacteria. J. Gen. Microbiol. 130:527-533.

Kemp, P., R. R. White, and D. J. Lander. 1975. The hydrogenation of unsaturated fatty acids by five bacterial isolates from the sheep rumen, including a new species. J. Gen. Microbiol. 90:100-114.

Legendre, P., and L. Legendre. 1998. Numerical Ecology. 2nd ed. Elsevier, Amsterdam, the Netherlands.

Loisel, P., J. Harmand, O. Zemb, E. Latrille, C. Lobry, J.-P. Delgenès, and J.-J. Godon. 2006. Denaturing gradient electrophoresis (DGE) and single-strand conformation polymorphism (SSCP) molecular fingerprintings revisited by simulation and used as a tool to measure microbial diversity. Environ. Microbiol. 8:720-731.

Loor, J. J., K. Ueda, A. Ferlay, Y. Chilliard, and M. Doreau. 2004. Biohydrogenation, duodenal flow, and intestinal digestibility of trans fatty acids and conjugated linoleic acids in response to di- 
etary forage:concentrate ratio and linseed oil in dairy cows. J. Dairy Sci. 87:2472-2485.

Loor, J. J., K. Ueda, A. Ferlay, Y. Chilliard, and M. Doreau. 2005. Intestinal flow and digestibility of trans fatty acids and conjugated linoleic acids (CLA) in dairy cows fed a high-concentrate diet supplemented with fish oil, linseed oil, and sunflower oil. Anim. Feed Sci. Technol. 119:203-225.

Lourenço, M., E. Ramos-Morales, and R. J. Wallace. 2010. The role of microbes in rumen lipolysis and biohydrogenation and their manipulation. Animal 4:1008-1023.

Michelland, R. J., S. Dejean, S. Combes, L. Fortun-Lamothe, and L. Cauquil. 2009. StatFingerprints: A friendly graphical interface program for processing and analysis of microbial fingerprints profiles. Mol. Ecol. Resour. 9:1359-1363.

Moate, P. J., W. Chalupa, T. C. Jenkins, and R. C. Boston. 2004. A model to describe ruminal metabolism and intestinal absorption of long chain fatty acids. Anim. Feed Sci. Technol. 112:79-105.

Park, P. W., and R. E. Goins. 1994. In situ preparation of fatty acid methyl esters for analysis of fatty acid composition in foods. J. Food Sci. 59:1262-1266.

Piperova, L. S., J. Sampugna, B. B. Teter, K. F. Kalscheur, M. P. Yurawecz, Y. Ku, K. M. Morehouse, and R. A. Erdman. 2002. Duodenal and milk trans octadecenoic acid and conjugated linoleic acid (CLA) isomers indicate that postabsorptive synthesis is the predominant source of cis-9-containing CLA in lactating dairy cows. J. Nutr. 132:1235-1241.

Pottier, J., M. Focant, C. Debier, G. De Buysser, C. Goffe, E. Mignolet, E. Froidmont, and Y. Larondelle. 2006. Effect of dietary vitamin $\mathrm{E}$ on rumen biohydrogenation pathways and milk fat depression in dairy cows fed high-fat diets. J. Dairy Sci. 89:685-692.

Privé, F., S. Combes, L. Cauquil, Y. Farizon, F. Enjalbert, and A. Troegeler-Meynadier. 2010. Temperature and duration of heating of sunflower oil affect ruminal biohydrogenation of linoleic acid in vitro. J. Dairy Sci. 93:711-722.

Roy, A., A. Ferlay, K. J. Shingfield, and Y. Chilliard. 2006. Examination of the persistency of milk fatty acid composition responses to plant oils in cows fed different basal diets, with particular empha- sis on trans-C18:1 fatty acids and isomers of conjugated linoleic acid. Anim. Sci. 82:479-492.

Shingfield, K. J., S. Ahvenjärvi, V. Toivonen, A. Vanhatalo, P. Huhtanen, and J. M. Griinari. 2008. Effect of incremental levels of sunflower-seed oil in the diet on ruminal lipid metabolism in lactating cows. Br. J. Nutr. 99:971-983.

Tricon, S., G. C. Burdge, S. Kew, T. Banerjee, J. J. Russell, E. L. Jones, R. F. Grimble, C. M. Williams, P. Yaqoob, and P. Calder. 2004. Opposing effects of cis-9,trans-11 and trans-10,cis-12 conjugated linoleic acid on blood lipids in healthy humans. Am. J. Clin. Nutr. 80:614-620.

Troegeler-Meynadier, A., L. Bret-Bennis, and F. Enjalbert. 2006. Rates and efficiencies of reactions of ruminal biohydrogenation of linoleic acid according to $\mathrm{pH}$ and polyunsaturated fatty acids concentrations. Reprod. Nutr. Dev. 46:713-724.

Troegeler-Meynadier, A., M. C. Nicot, C. Bayourthe, R. Moncoulon, and F. Enjalbert. 2003. Effects of $\mathrm{pH}$ and concentrations of linoleic and linolenic acids on extent and intermediates of ruminal biohydrogenation in vitro. J. Dairy Sci. 86:4054-4063.

Van Nevel, C. J., and D. I. Demeyer. 1996. Influence of pH on lipolysis and biohydrogenation of soybean oil by rumen contents in vitro. Reprod. Nutr. Dev. 36:53-63.

Wallace, R. J., L. C. Chaudhary, N. McKain, N. R. McEwan, A. J. Richardson, P. E. Vercoe, N. D. Walker, and D. Paillard. 2006. Clostridium proteoclasticum: A ruminal bacteria that forms stearic acid from linoleic acid. FEMS Microbiol. Lett. 265:195-201.

Weimer, P. J., D. M. Stevenson, and D. R. Mertens. 2010. Shifts in bacterial community composition in the rumen of lactating dairy cows under milk fat-depressing conditions. J. Dairy Sci. 93:265278.

Winkler, K., and H. Steinhart. 2001. Identification of conjugated isomers of linolenic acid and arachidonic acid in cheese. J. Sep. Sci. 24:663-668.

Yang, S. L., D. P. Bu, J. Q. Wang, Z. Y. Hu, D. Li, H. Y. Wei, L. Y. Zhou, and J. J. Loor. 2009. Soybean oil and linseed oil supplementation affect profiles of ruminal microorganisms in dairy cows. Animal 3:1562-1569. 